\title{
INVESTIGATIONS ON WEAR AND FRICTION IN THE SI ENGINE VALVETRAIN
}

\author{
Marek WOŹNIAK ${ }^{1)}$, Cristina Florena BANICA ${ }^{2)}$, \\ Mihai DIACONU ${ }^{2)}$, Gustavo OZUNA ${ }^{3)}$, Piotr JÓŹWIAK ${ }^{1)}$, Krzysztof SICZEK $^{1)}$ \\ ${ }^{1)}$ Department of Vehicles and Fundamentals of Machine design, Lodz University of Technology, Poland \\ ${ }^{2)}$ Faculty of Mechanics and Technology, University of Pitesti, Romania, \\ ${ }^{3)}$ Department of Industrial Engineering and Systems, University of Sonora, Mexico,
}

marek.wozniak@p.lodz.pl,banicacristina22@yahoo.com,

mihai.diaconu23@yahoo.com,gozuna@industrial.uson.mx

\begin{abstract}
The engine valvetrain system operating under conditions of insufficient oil lubrication, caused by incorrect installation of the gasket between the block and the head, was tested. The aim of the analysis was to determine the wear intensity and resistance to motion in camshaft bearings. A model was developed that includes a camshaft, bearings, tappet-valve-spring subassemblies and a part of the lubrication system. It was used to determine the bearing loads and the amount of oil supplied. The volumetric wear of the camshaft journals and bearing covers was measured. For the estimated engine run, the wear rate and resistance to motion were compared for the cases of the engine with correct and incorrect lubrication.
\end{abstract}

Keywords: Camshaft bearings, gasket, friction, abrasion wear, lubrication system

\section{INTRODUCTION}

The proper operation of the internal combustion engine is conditioned by the correct operation of all its components, especially critical ones, such as the valvetrain. The valvetrain contributes $6-10$ per cent of the total frictional loss in an engine [4]. Excessive resistance to motion and wear of mating valvetrain elements result in increased fuel consumption, increased oil contamination by wear and combustion particles, local temperature rise and increased noise and vibration levels that may affect this wear and friction in feedback.

The problems of the theory of wear of the moving elements of the CI engine valvetrain systems and the analysis of the phenomena occurring in the sliding contact and the mathematical description of the processes occurring are presented in the paper [18].

According to [11], the running-in wear of automotive cam-follower systems was assessed from tests carried out using a motored PSA TU3 cylinder head. The changes in surface topography occurring through wear can be a basis for establishing an objective method of wear evaluation.

According to [12], preventing valvetrain wear in engines is one of the most important properties of an engine oil. The antiwear performance of additives (such as ashless dispersants, metallic detergents and zinc dithiophosphate - ZDTP) and the influence of the interaction of the additives were evaluated therein. Also, the influence of calcium sulphonate and an overbased phenate on the anti-scuffing performance in engine tests and in Falex wear tests were investigated. Finally, the interaction of ZDTP, succinimides and calcium detergents and their influence on valvetrain wear were studied.

According to [3], motored single cam lobe valvetrain experiments were conducted to evaluate the wear protection capability of several $0.05 \mathrm{wt} \% \mathrm{P}$ containing engine oils while the oil is fresh. The wear protection capability of vehicle drain samples was also evaluated. It was observed that used oils provided improved wear protection capability coupled with reduced friction. It was found that the composition of lubricant-derived protective films formed with used oils significantly differs from that formed with fresh oil, which may explain improved wear characteristics and reduced friction with used oils.

In [4] it was described attempts to reduce frictional losses in direct acting mechanical bucket tappet type valvetrains through surface finish, surface texture and coatings. It was observed that surface 
finish and surface texture could reduce frictional losses, but engine oil formulation also plays a significant role. Improvements were observed with non-friction-modified oils, but with friction-modified oils the overall friction was lower but no additional friction benefit could be observed with surface finish or surface texture. It was also found that implementation of proposed GF-4 low-phosphorus engine oils formulated properly provide similar or better wear protection compared with GF-3 oils containing 0.1 per cent phosphorus..

In [1], it was studied the effect of viscosity on wear under conditions of boundary lubrication occurring in the tester simulating the camshaft-lifter contact in an engine. Viscosity reduction was shown to have a profound effect on wear once a critical viscosity had been reached. It was found that wear prevention occurs due a mixture of localized elastohydrodynamic lubrication and surface films formed from the anti-wear additive. Loss of them results in excessive wear.

According to [6] camshaft bearing failure can be caused by excessive wear. Under high load the thickness of the oil film decreases. If the minimum oil film thickness is lower than the micro-asperities on the bearing and journal surfaces, the hydrodynamic lubrication is compromised and metal-to-metal contact between the surfaces is established. Direct friction results in fast wear of the bearing material.

Another factor often causing camshaft bearing failure is misalignment. The bearing and the camshaft surfaces should be aligned when the camshaft is installed in the engine. However, distortions of the block induced by thermal or mechanical stresses cause misalignments of the bearings. Then some of the camshaft bearings start to operate in a constant metal-to-metal contact with the journal surface and their lining wears fast. The alignment of the distorted camshaft bearings housings may be reconditioned by oversize boring. Oversized camshaft bearings must be used in such engines.

Excessive wear of camshaft bearings may also be caused by oil starvation conditions at cold start of the engine. The oil path to the camshaft bearings is long in some engines. Therefore it takes some time for cold oil to reach the bearing surface. At each cold start the camshaft bearings operate in the absence of oil, causing metal-to-metal contact.

Oil starvation may be also a result from an excessive leakage of oil due to the large bearing clearance. In contrast to cold start, a reduction of the oil pump pressure caused by leakage occurs mostly with hot low viscosity oils.

Typical oil clearance of camshaft bearings is (0.0015-0.002) D, where $D$ is the bearing diameter [6].

For the long-term correct operation of the engine timing elements, it is necessary to perform the necessary repairs, in addition to their utilization in the agreement with recommendations of the manufacturer. During their performance, a lot of attention must be paid to the process of disassembly and assembly of components. Incorrect combinations of components may result in serious disruptions in the repaired engine and quickly lead to malfunctions. An example of this was the incorrect placement of the gasket between the cylinder block and the head of the internal combustion engine. This has led to a significant reduction in the amount of oil fed to the camshaft bearings and then to their seizing and failure of the entire engine.

The purpose of the present analysis was to investigate the effect of created conditions of limited lubrication of camshaft bearings on the resistance to motion and wear intensity in the conditions of the engine's working cycle.

\section{Methods and Materials}

\subsection{Engine and its Valvetrain}

The research object was the valvetrain of the four-cylinder SI R4 1.2 8V engine cooled with liquid, used in the FIAT Punto II from 2005. The cylinder diameter and stroke for this engine was $70.8 \times 78.86$ $\mathrm{mm}$, which corresponded to the engine capacity of $1242 \mathrm{~cm}^{3}$. Its compression ratio was 9.8:1, and the brake mean effective pressure (bmep) was of 1032 $\mathrm{kPa}$. The engine, according to the manufacturer, achieved a maximum torque of $102 \mathrm{Nm}$ at $2500 \mathrm{rpm}$ and a maximum power of $44 \mathrm{~kW}$ at $5000 \mathrm{rpm}$. Exemplary graphs of measured values of engine power and torque as a function of rotational speed are shown in Fig. 1. They were about $10 \%$ smaller than the values given by the manufacturer.

The engine's timing was fixed, including one steel inlet and outlet valve per cylinder, driven by one camshaft. The return of each valve was carried out by a steel valve spring cooperating with it. The steel camshaft was driven from the crankshaft via a toothed belt with a tensioner.

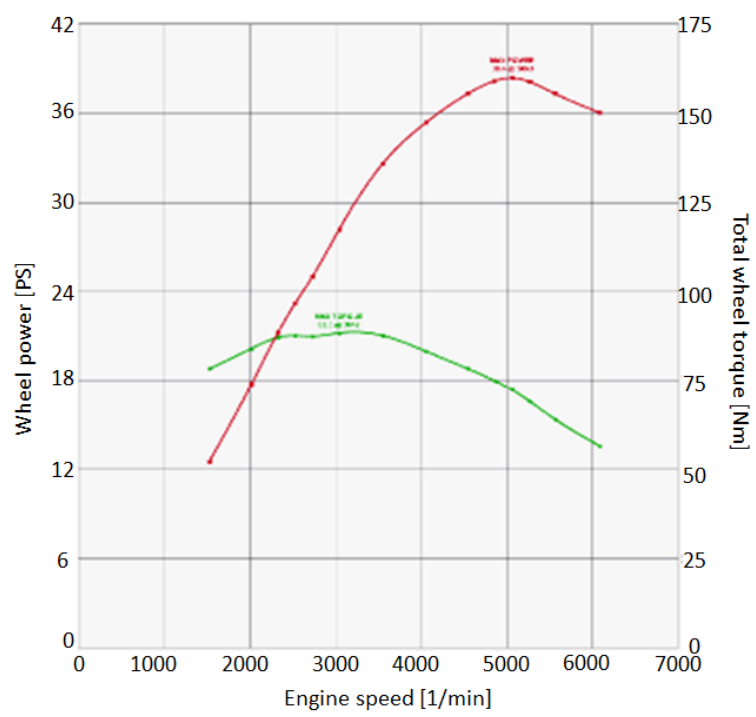

Fig. 1. Exemplary waveforms of measured engine power and torque as a function of engine speed for the engine SI R4 1.2 8V FIAT Punto II 2005

The diagram of valve lift as a function of the angle of camshaft rotation is shown in Fig. 2. This graph 
also shows the modelled course of pressure in the cylinder in the initial phase of opening the outlet valve. A high pressure drop is then observed as a function of the angle of camshaft rotation.

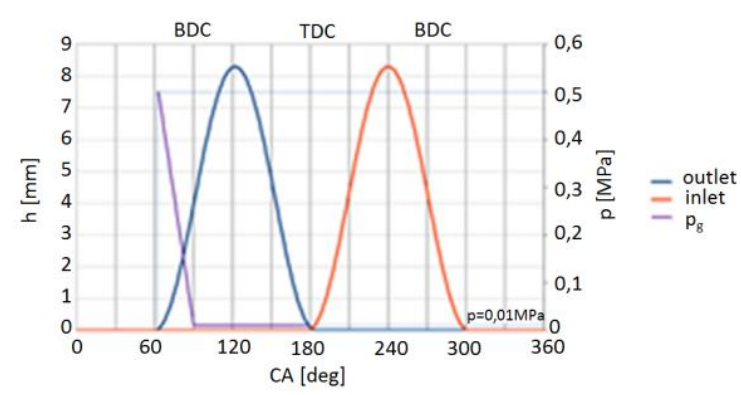

Fig. 2. The graph of valve lifts and modelled pressure $\mathrm{p}_{\mathrm{g}}$ in the cylinder as a function of camshaft rotation for the engine SI R4 1.2 8V FIAT Punto II 2005

\subsection{Camshaft Bearings}

The camshaft 4 has radial bearings in three hubs $1,2,3$ of slide bearings made of aluminum alloy, lubricated with engine oil supplied through the stub 6 from the channel in the cylinder head. Axial bearing is realized by means of a sliding thrust bearing placed in hub 1.

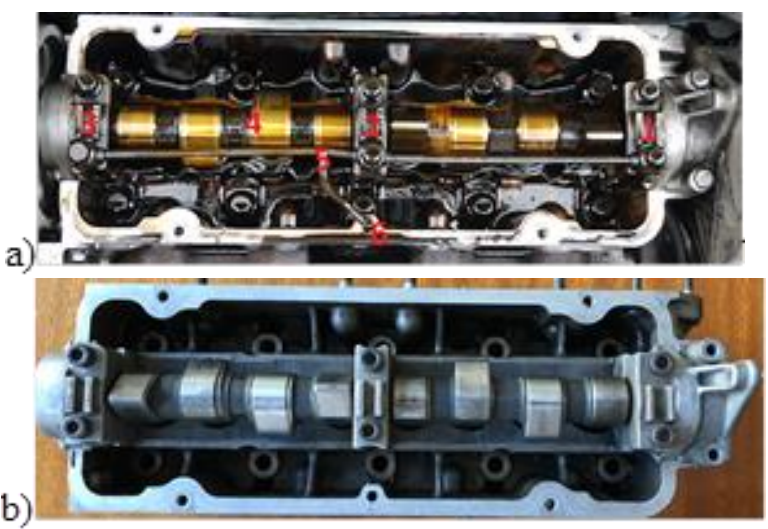

Fig. 3. Elements of the valvetrain system in the engine SI R4 1.2 8V FIAT Punto II 2005. a) on the engine, $\mathrm{b}$ ) outside the engine. 1, 2, 3 - bearing covers, 4 - camshaft, 5 - oil main line for camshaft bearing, 6 stub at the outlet of the oil channel in the head

\subsection{Camshaft Bearing Lubrication System}

For lubricating the bearings, engine oil supplied from the engine oil sump through the system of canals was used, under the pressure generated by a gear pump with internal toothing. The wheel with external teeth with the number of teeth $z_{I}=11$ was placed at the end of the crankshaft and directly driven from it. It mated with the internal teeth of the pump with the number of teeth $z_{2}=13$. The gearing module was $m=4$, and the operating tooth width was $B=13 \mathrm{~mm}$. The working pressure of the oil was $70 \mathrm{kPa}$ at idle and $400 \mathrm{kPa}$ at $4000 \mathrm{rpm}$ of the internal combustion engine.

A linear dependence of oil pressure on the shaft speed was assumed. In fact, it is non-linear due to the flow resistance and operation of the pressure limiting valve in the oil bus. It was assumed that for existing pressures the overall efficiency of the pump is constant and amounts to 0.7 , and the pump efficiency does not depend on the value of the oil transfer pressure.

The efficiency of the gear oil pump is determined by the formula (1) [13]:

$$
\begin{aligned}
Q_{r}= & 0.5 B\left\{r_{a 1}^{2}-\left(r_{w 1} / r_{w 2}\right) r_{a 1}^{2}-r_{w 1}\left(r_{w 1}{ }^{-}\right.\right. \\
& \left.\left.-r_{w 2}\right)-\left[\left(1-\left(r_{w 1} / r w 2\right)\right) u^{2}\right]\right\}
\end{aligned}
$$

where $r_{a l}=0.5\left(z_{1}+2\right) m$ - the external radius of the external gear wheel, $r_{a 2}=0.5\left(z_{2}+2\right) m$ - the external radius of the internal gear, $r_{w 1}=0.5 z_{1} m$ - the radius of the gear wheel with external teeth, $r_{w 2}=0.5 z_{2} m$ - the radius of the gear wheel with internal gearing.

The $u$ parameter is estimated from the formula (2) [13]:

$$
u \approx \pi r_{a 1} / z_{1}
$$

Estimations of oil inlet velocity for individual contact zones in bearings were made using a model developed using the finite element method and shown in Fig. 4.

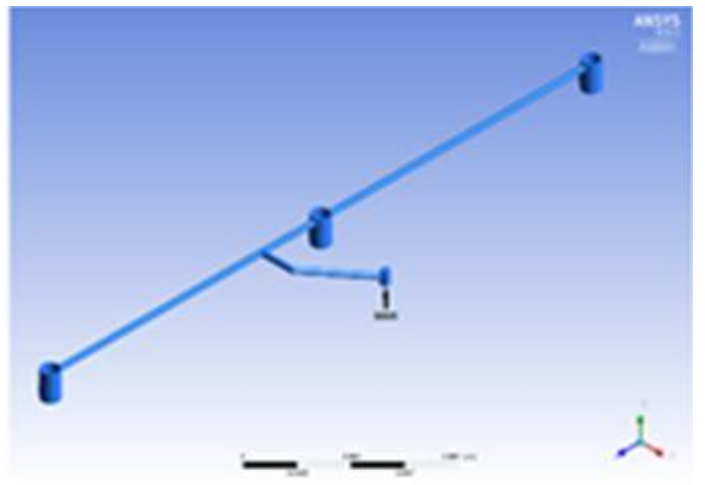

a)

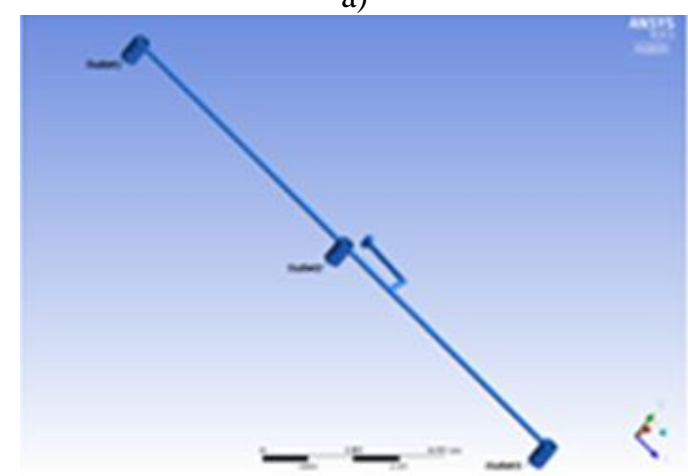

b)

Fig. 4. Model of the controlled oil volume. a) (Inlet) place of oil supply to the channel in the cylinder head, b) (Outlet1, Outlet2, Outlet3) - oil outlets into friction contact zones in camshaft bearings, c) finite element mesh

This model contains a controlled volume of flowing oil from the place of its supply (Inlet - Fig. 4a) to the channel in the cylinder head, to its outlets (Outlet 1, Outlet2, Outlet3 - Fig. 4b) into the friction contact zones in camshaft bearings. The analyzed oil had physical properties similar to that of SAE 5W-40 oil, its molar mass was of $300 \mathrm{~kg} / \mathrm{kmol}$, density of 
$856 \mathrm{~kg} / \mathrm{m}^{3}$, specific heat of $2000 \mathrm{~J} / \mathrm{kgK}$, dynamic viscosity of $0.013 \mathrm{~kg} / \mathrm{ms}$, and thermal expansion of $0.13 \mathrm{~W} / \mathrm{mK}$. The boundary condition was introduced on the in the form of:

a) mass flow $0.00035 \mathrm{~kg} / \mathrm{s}$,

b) a constant pressure of $400 \mathrm{kPa}$ on the oil inlet, and an ambient pressure condition was introduced at the outlets. On the remaining surfaces limiting the controlled volume of oil, the condition of rigid smooth walls was assumed, on which there is no liquid slip. The assumption of a fluid flow with constant properties and constant temperature of 353 $\mathrm{K}$ (which corresponds to the temperature value of the motor thermal balance) was assumed with the allowed occurrence of turbulences (model k- $\mathrm{k}$ ). The grid of finite elements is shown in Fig. 4c.

\subsection{The Influence of the Gasket Position on Oil Flow in the Main Line for Camshaft Bearing}

The oil flow in the main line for camshaft bearing is affected by the flow resistance. In the case of correct placement of the gasket, it does not exceed the flow resistance provided by the engine manufacturer. The engine oil is subject to filtration and has cleaning additives on its own, so it is unlikely that debris and pollutions will permanently deposit in the oil channels generating congestions that impede or even block oil flow.

With the gasket correctly seated (Fig. 5a), the cross-sectional area of the pocket (Fig. 5c) placed before entering the oil main line for camshaft bearings and supplying oil into them was of $146 \mathrm{~mm}^{2}$ (circumference of $49 \mathrm{~mm}$ ). When the gasket is in the wrong position (Fig. 5b), the cross-sectional area of the said pocket has been reduced to approximately 9 $\mathrm{mm}^{2}$ (circumference $12 \mathrm{~mm}$ ).

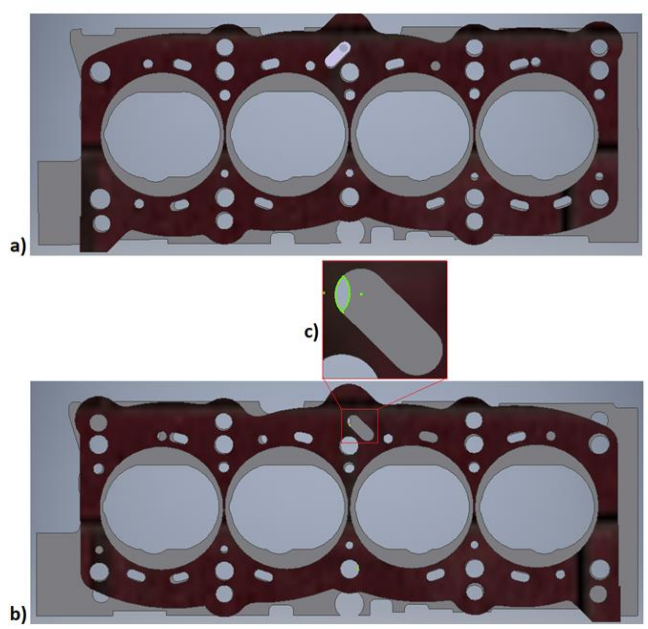

Fig. 5. Arrangement of the gasket relative to the head, a) correct, b) incorrect, c) enlarging the view of the pocket before entering the oil main line for camshaft bearings

\subsection{The Model of the Tappets-Camshaft-Bearings Assembly}

The camshaft is subjected to a load from the torque which is balanced by the moments of forces resulting from the action of the tappets on the cam side surfaces and the mass moment of inertia of the camshaft. The force $F$ of the tappet's action on the shaft cam is a resultant of the spring force $S$, the inertial force $B_{v}$ of the valve, and in the case of the outlet valve also the gas force $P_{g}$ acting on it in the initial period of its opening, as described by the formula (3).

The physical model of the tappets-camshaftbearings assembly is shown in Fig. 6. The geometry of a single tappet has been simplified to a cylinder with a finite length. Each tappet was loaded with a force $F$ which resulted from the angular position and the rotational speed of the camshaft.

$$
F=S+B_{v}+P_{g}
$$

The spring force was determined from the formula (4):

$$
S=k\left(h_{v}+h_{s 0}\right)
$$

where: $k=18.89 \mathrm{~N} / \mathrm{mm}$ - estimated spring rate, $h_{v}$ valve lift, $h_{s 0}=7 \mathrm{~mm}$ - measured initially loaded spring deflection.

The $P_{g}$ force from the gas force acting on the outlet valve was calculated from the formula (5):

$$
P_{g}=0.25 \pi d_{\text {aver }}^{2} p_{g}
$$

where $d_{\text {aver }}-$ mean valve seat diameter, $p_{g}-$ gas pressure in the cylinder.

The course of pressure $p_{g}$ as a function of rotation angle $\alpha$ of the camshaft is shown in Fig. 2 .

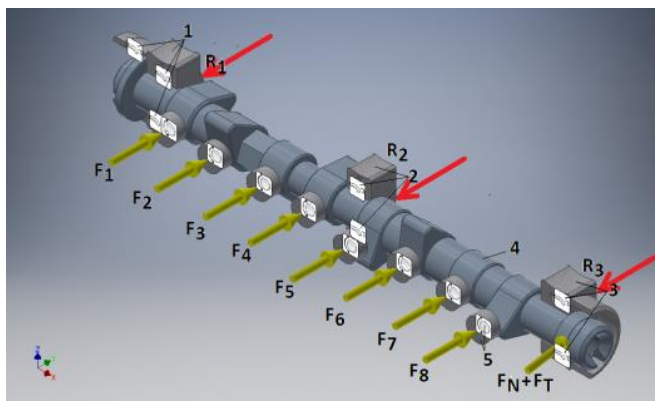

a)

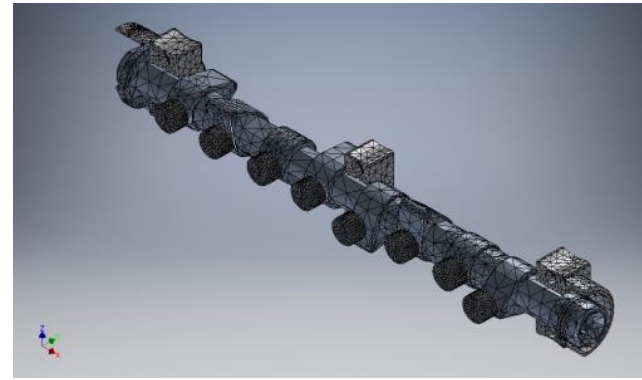

b)

Fig. 6. a) The model of the tappets-camshaft-bearings assembly, b) Finite element grid. 1, 2, 3 - bearing covers with fixed surfaces located on the plane containing camshaft bearings axles, 4 - cam shaft, 5 tappet with fixed axis of rotation, $F_{1}, F_{2}, F_{3}, F_{4}, F_{5}$, $F_{6}, F_{7}, F_{8}$ - forces loading the consecutive tappets mating with the shaft cams $4, F_{N}$ - force from the toothed belt tension, $F_{T}$ - force resulted from the part of the drive torque acting on the toothed pulley mounted on the camshaft, $R_{1}, R_{2}, R_{3}$ - reactions in bearings $1,2,3$ 
The inertia force was determined from the formula (6):

$$
B_{v}=\left(m_{v}+m_{t}+0.5 m_{s}\right)\left(d^{2} h / d \theta^{2}\right) \omega_{c}^{2}
$$

where $m_{v}$ - valve mass, $m_{t}$ - tappet mass, $m_{s}$ - spring mass.

During the mating of the camshaft 1 with the tappets 2, the camshaft bearings are loaded substantially on the side of the bearing covers 3, the width of which is practically constant. Therefore, only the bearing covers 3 were considered in the physical model, and the bearings themselves were modeled as short fixed bearings.

The camshaft journal with the embedded wheel 1 of the toothed belt 5 is loaded by (Fig. 7):

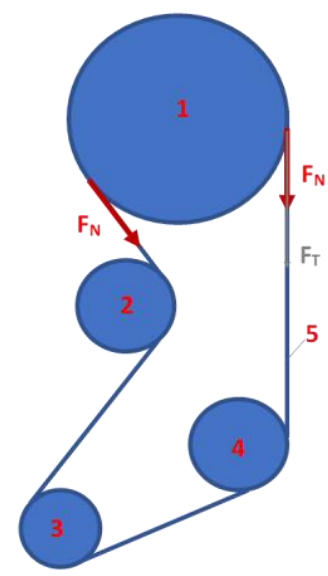

Fig. 7. Forces from the toothed belt loading the timing pulley. 1 - toothed pulley on the camshaft, 2 tensioner, 3 toothed pulley on the crankshaft, 4 toothed pulley on the water pump shaft, 5 - toothed belt. $F_{N}$ - force from the toothed belt tension, $F_{T}$ force resulted from the part of the driving torque on the engine crankshaft.

- force $F_{N}=200 \mathrm{~N}$ from the belt tension caused by the tensioner 2 operation,

- force $F_{T}$ resulted from a part of the drive torque on the crankshaft 3 transmitted via the toothed belt 5 to the camshaft 1 and the water pump drive shaft 4 .

The force arm $R_{c}$ is determined by the formula (7)

$$
R_{c}=R_{c}+h+\left(d^{2} h / d \theta^{2}\right) \omega_{c}^{2}
$$

where: $R_{b}$ - camshaft cam radius, $h_{v}$ - valve lift, $\omega_{c}$ camshaft rotational speed, $\theta$ - camshaft rotation angle.

The $F_{T}$ force from the driving torque is estimated from the formula (8):

$$
F_{T}=2 d_{\text {ave }}^{-1} \sum_{i=1}^{i=8} F_{i} \cdot R_{c i}
$$

where: $d_{\text {ave }}$ - pitch diameter of toothed pulley on the camshaft.

The model of the tappets-camshaft-bearings assembly was developed using the Finite Element Method and shown in Fig. 6. The surfaces of the bearing covers $1,2,3$, located in the plane containing cam roller bearings axes were fixed. The model incorporates contact elements on the mating surfaces of the cams the shaft 4 and the front surfaces of the tappets 5 and on surfaces of journals the camshaft 4 and the bearing surfaces of the covers 1,2,3 mating with them. The axes of the tappets 5 have been fixed. The tappets 5 have been loaded with forces $F_{1}, F_{2}$, $F_{3}, F_{4}, F_{5}, F_{6}, F_{7}, F_{8}$, acting along these fixed axes. The cylindrical surface of the end of the camshaft 4 on which the toothed pulley is mounted has been loaded by force resulting from the force $F_{N}$ from the tension of the toothed belt and the force $F_{T}$ from the part of the drive torque acting on the toothed pulley mounted on the camshaft.

The calculations were carried out for the selected angular position of the camshaft set for two values of the rotational speed of the cam shaft $750 \mathrm{rpm}$ and 2000 rpm.

\subsection{The Model of the Resistance to Motion}

The camshaft journals are subjected to friction during its motion relative to bearing shells. The friction torque $M_{T i}$ depends on the reaction in the $i$-th bearing, the diameter of the journal $D_{i}$ and the coefficient of friction $f$, which depends on many factors, in particular on the value of contact stresses $p_{c}$, slip speed $v_{c}$, surface layer properties, contact geometry, lubricant properties, if present and the presence of environmental pollution and humidity. This is represented by the formula (9):

$$
M_{T i}=0.5 f\left(p_{c}, v_{c}, \text { oil }, \text { contact geomtry }\right) R_{i} D_{i}
$$

It was assumed that within the analyzed engine cycles, the level of pollution and humidity is constant, the engine operates at the temperature of the heat balance, so the lubricating properties of the oil do not change.

Two cases are considered:

1. The camshaft bearings operate in the presence of oil supplied from the main line for camshaft bearings, and then mixed or boundary friction conditions occur in the contact zone.

2. The camshaft bearings operate in the absence of oil conditions and then the conditions of technically dry friction occur.

In the first case, the Greenwood-Tripp model was adopted to determine the resistance of movement in the interface between inequalities of mating surfaces [10]. The actual contact surface is determined from the formula (10) [10]:

$$
A_{r i}(\bar{h})=\pi^{2}\left(\eta_{s} \beta_{s} \sigma_{s}\right)^{2} A_{0 i} F_{2}(\bar{h})
$$

where: $A_{0}-$ the average (contour) contact surface area determined from the FEM model or from the formula (11), bearing in mind that the camshaft journal radius is close to one of its bearing cover hole, $\quad \bar{h}=\left(h-Z_{s}\right)^{2} / \sigma_{s}-$ normalized average distance of the contact surfaces.

The average (contour) contact surface area was determined from the formula (11) [19]:

$$
\begin{aligned}
A_{o i} & =L_{i} D_{i} \varphi_{i 0} \approx \\
& \approx L_{i} D_{i}\left(1.52 \sqrt{\frac{\left[\left(1-v_{1}^{2}\right) / E_{1}+\left(1-v_{2}^{2}\right) / E_{2}\right] R_{i}}{L_{i} C_{i}}}\right)
\end{aligned}
$$


where $L_{i}-$ width, $D_{i}-$ diameter, $C_{i}-$ clearance of the $i$-th bearing.

Average contact stresses were determined from the formula (12) [10]:

$$
p_{c}(\bar{h})=(16 / 15) 16 \pi \sqrt{2} E^{*}\left(\eta_{s}^{2} \beta_{s}^{3 / 2} \sigma_{s}^{5 / 2}\right)^{2} F_{s / 2}(\bar{h})
$$

The load transmitted by the metallic contact of surface unevenness in the bearing can be determined from the formula (13):

$$
R_{c o n}=p_{c}(\bar{h}) A_{0}
$$

The replacement Young's modulus was determined from the formula (14) [19]:

$$
1 / E^{*}=\left(1-v_{1}^{2}\right) / E_{1}+\left(1-v_{2}^{2}\right) / E_{2}
$$

where: $E_{1}=210000 \mathrm{MPa}, E_{2}=70000 \mathrm{MPa}$ Young's modulus, $v_{l}=0.3, v_{2}=0.33$ - Poisson's number for the material of the camshaft journal and bearing shell, respectively [7], [5].

The parameter values were assumed, as follows: $Z_{s 1}=Z_{s 2}=R a=0.8 \mu m$ - the average height of the surface asperities for the camshaft journal and its bearing shell, $\sigma_{s 1}=\sigma_{s 2}=0.3 \cdot R a=0.24 \mu m$ - the average standard deviation of the surface asperities' height for the journal and the bearing shell.

The average radius of surface asperities for camshaft journal $(l=1)$ and the bearing shell $(l=2)$ was determined from the formula (15) [8]:

$$
\beta_{s l}=0.05 S_{m l}^{2} / R a
$$

where: $S_{m l}=0.025-0.1 \mathrm{~mm}$ for steel precision ground outer surfaces of cylindrical cam shaft journals [8]. It has been assumed, on the basis of initial tests of lapped bearings, that the $S_{m 2}$ values for the lapped inner surfaces of bearing shells made of the aluminium alloy are in the range 0.0048-0.1 mm.

The values of parameter $\beta_{s 1}$ were within 0.039 $0.625 \mathrm{~mm}$, and of $\beta_{s 2}$ within $0.0014-0.625 \mathrm{~mm}$.

The average density of surface asperities was determined from the formula (16) [10]:

$$
\eta_{s 1}=\eta_{s 2}=\bar{N} / A_{0}
$$

The number of asperities on the rough contact surface has been estimated from the formula (17):

$$
\bar{N}=A_{0} /\left(50 \cdot R_{a}\right)^{2}
$$

It was assumed that:

- the team average height of the contact surface asperities is determined from the formula (18) [10]:

$$
Z_{s}=Z_{s 1} \sqrt{2}
$$

- the team average standard deviation of the contact surface asperities height is determined from the formula (19) [10]:

$$
\sigma_{s}=\sigma_{s 1} \sqrt{2}
$$

- the team average radius of contact surface asperities is determined from the formula (20) [10]:

$$
\beta_{s}^{-1}=\sqrt{\beta_{s 1}^{-2}+\beta_{s 2}^{-2}}
$$

Its values may vary within the range of $0.0014-$ $0.44 \mathrm{~mm}$.

- the team average density of contact surface asperities was determined from the formula (21) [10]:

$$
\eta_{s}=\eta_{s 1} \sqrt{2}
$$

The function $F_{s / 2}(\bar{h})$ was approximated according to the formula (22) [15]:

$$
\begin{gathered}
F_{s / 2}(\bar{h})=0.1667-0.0776 \bar{h}+0.7844 \bar{h}^{2}- \\
-0.2958 \bar{h}^{3}+0.0574 \bar{h}^{4}-0.0046 \bar{h}^{5}
\end{gathered}
$$

The function $\mathrm{F}_{2}(\overline{\mathrm{h}})$ was approximated according to the formula (23) [15]:

$$
\begin{gathered}
F_{2}(\bar{h})=0.5003-0.8043 \bar{h}+0.5258 \bar{h}^{2}- \\
-0.1728 \bar{h}^{3}+0.0282 \bar{h}^{4}-0.0018 \bar{h}^{5}
\end{gathered}
$$

It was assumed that the mating bearing surfaces had isotropically oriented roughness, therefore the surface texture parameter $\gamma$ was 1 .

Part of the reaction in the bearing transmitted by the hydrodynamic force and the resistance to motion dependent on it was determined using the averaged Reynolds equation (24) for the bearing with rough surfaces [17].

$$
\begin{aligned}
& 12 \Phi_{s} \frac{\partial h}{\partial t}+\sigma U \frac{1}{R}\left(\Phi_{c} \frac{\partial h}{\partial \varphi}+\sigma \frac{\partial \Phi_{s}}{\partial \varphi}\right)= \\
& =\frac{\partial}{R \partial \varphi}\left(\Phi_{x} \frac{h^{3}}{\mu} \frac{\partial p}{R \partial \varphi}\right)+\frac{\partial}{\partial z}\left(\Phi_{z} \frac{h^{3}}{\mu} \frac{\partial p}{\partial z}\right)
\end{aligned}
$$

It was assumed that the value of the team average standard deviation of the roughness height $\sigma_{R}$ is close to the value of the team average standard deviation of the surface asperities' height $\sigma_{s}$, so $\sigma_{R} \approx \sigma_{s}$.

Then the value of the oil film thickness coefficient $\Lambda=h / \sigma_{R}$ for boundary lubrication is of 6.7 , i.e. it is higher than 1 , which makes it possible to estimate values of the pressure effect coefficients $\Phi_{x}=\Phi_{z}$ from the formula (25) [9], [10], [17]

$$
\Phi_{\mathrm{x}}=\Phi_{\mathrm{z}}=1+\mathrm{C}_{\varphi} \Lambda^{-\mathrm{r}_{\varphi}}
$$

For the parameter value $\gamma=1$, the estimated parameters' values are $C_{\varphi}=0.9$ and $r_{\varphi}=0.56$, respectively. Then the estimated values of the pressure effect coefficients $\Phi_{x}=\Phi_{z}$ are of 1.31 .

For the value of the coefficient $\Lambda$ higher than 5 and the parameter value $\gamma=1$, the shear stress effect coefficient was estimated from the formula (26) [9], [10], [17]:

$$
\begin{gathered}
\Phi_{s}=\left(\sigma_{R 1} / \sigma_{R}\right)^{2} 1.126 e^{-0.25 \Lambda}- \\
-\left(\sigma_{R 2} / \sigma_{R}\right)^{2} 1.126 e^{-0.25 \Lambda}
\end{gathered}
$$

Because there is a dependence $\sigma_{R}=\sigma_{R I} \sqrt{2}=\sigma_{R 2} \sqrt{2}$, the coefficient value $\Lambda=6.7$ corresponds to the coefficient value $\phi_{s}=0$.

The coefficient value $\Lambda=6.7$ corresponds to the contact coefficient value $\phi_{c}=1$ [9], [10], [17].

For the so-determined coefficients, the formula (24) is simplified to the form (27): 


$$
\sigma U \frac{1}{R} \frac{\partial h}{\partial \varphi}=\frac{\partial}{R \partial \varphi}\left(\Phi_{x} \frac{h^{3}}{\mu} \frac{\partial p}{R \partial \varphi}\right)+\frac{\partial}{\partial z}\left(\Phi_{z} \frac{h^{3}}{\mu} \frac{\partial p}{\partial z}\right)
$$

In order for the average Reynolds equation to be dimensionless, convenient for numerical solution, several dimensionless quantities were introduced. For the sliding bearing, the thickness $h$ of the oil film can be determined from the formula (28) [14]:

$$
h=C H=C(1+\varepsilon \cos \theta)
$$

where $C=0.05 \mathrm{~mm}$ - radial clearance in camshaft bearing, $\theta$ - angle, $H=1+\varepsilon \cos \theta$ - dimensionless height.

Knowledge of eccentricity $e$ of the journal center relative to the bearing centre makes it possible to determine the relative eccentricity from the formula (29) [14]:

$$
\varepsilon=\mathrm{e} / \mathrm{C}
$$

The dimensionless pressure was determined from the formula (30) [14]:

$$
\bar{p}=\left\{p /\left[\mu n(R / C)^{2}\right]\right\}
$$

where $p=R_{H} /(D L)$ - nominal pressure transferred by hydrodynamic force in the contact area of the metallic bearing surface with grease, $R_{H}-$ hydrodynamic force in the contact area of the metallic bearing surface with grease, $R=D / 2$ bearing radius, $\mu$ [Pas] - dynamic viscosity of the lubricant, $n$ [rot/s] - rotation speed of the camshaft.

Because camshaft bearings can be treated as short bearings, therefore simplified formula (27) can be further simplified to the dimensionless form (31) [14]:

$$
12 \pi\left(\frac{\mathrm{L}}{\mathrm{D}}\right)^{2} \frac{\partial \mathrm{H}}{\partial \varphi}=\frac{\partial}{\partial \overline{\mathrm{z}}}\left(\Phi_{\mathrm{z}} \mathrm{H}^{3} \frac{\partial \overline{\mathrm{p}}}{\partial \overline{\mathrm{z}}}\right)
$$

with the following boundary conditions (32) [14]:

$$
\bar{p}=\bar{p}_{a} \text { for } \bar{z}= \pm 1
$$

the solution has the form (33) [14]:

$$
\bar{p}=\bar{p}_{a}+\left(6 \pi / \Phi_{z}\right)(L / D)^{2} H^{-3}(\partial H / \partial \varphi)\left(\bar{z}^{2}-1\right)
$$

The radial component of the reaction in the bearing is determined by the formula (34) [14]:

$F_{T R}=-W \cos \Phi=$

$=-(l / D)^{2}\left[4 \pi \varepsilon^{2} /\left(1-\varepsilon^{2}\right)^{2}\right] \operatorname{LD\mu n}(R / C)^{2}=(34)$

$=\int_{-L / 2}^{L / 2} \int_{0}^{R \theta_{c a v}} p \cos \theta d x d z$

The tangent component of the reaction in the bearing is determined by the formula (35) [14]:

$$
\begin{aligned}
& F_{T T}=-W \sin \Phi= \\
& =-(L / D)^{2}\left[\pi^{2} \varepsilon /\left(1-\varepsilon^{2}\right)^{3 / 2}\right] L D \mu n(R / C)^{2}= \\
& =\int_{-L / 2}^{L / 2} \int_{0}^{R \theta_{c a v}} p \sin \theta d x d z
\end{aligned}
$$

Angle deviation of the plane containing the bearing axis and the journal axis from the direction of external load operation was determined from the formula (36) [14]:

$$
\Phi=\operatorname{arctg}\left(0.25 \pi \sqrt{1-\varepsilon^{2}} \varepsilon^{-1}\right)
$$

Assuming that it occurs (37):

$$
\left|F_{T R}\right|=R_{\text {con }}+R_{H}
$$

and (38):

$$
F_{T T}=f_{H} R_{H}+f_{d r y} R_{c o n}
$$

where $f_{d r y}$ - the technically dry friction coefficient between steel and aluminium alloy, one can determine values of the force $R_{H}$ and the coefficient hydrodynamic resistance $f_{H}$.

The friction torque under the mixed friction conditions in the camshaft bearing was determined from the formula (39):

$$
M_{T T i}=\left(R_{\text {con }} f_{\text {idry }}+R_{H} f_{H}\right) R
$$

It was assumed that the value of the technically dry friction coefficient $f_{i d r y}$ at the contact zone of the camshaft journal surface with the bearing cover surface is close to 0.46 , obtained during the wear tests of the friction pair for the contact type of steel disc - pin from the aluminum casting alloy AK12 in the presence of air [2].

In the case where the operation of the $i$-th camshaft bearing takes place in the conditions of lack of oil and then the friction torque in the $i$-th bearing is determined from the formula (40):

$$
M_{T i}=0.5 f_{d r y} R_{i} D_{i}
$$

The total friction torque in the camshaft bearings is determined from the formula (41):

$$
M_{T}=\sum_{i=1}^{i=3} M_{T i}
$$

\subsection{The Model of Wear in the Camshaft Bearings}

The journals made of steel had higher hardness than the material of the mating surfaces of the bearing covers made of aluminum alloy. Therefore, in further analysis, it was assumed that under the mixed friction conditions only the bearing covers were worn, and the journal wear was omitted. It was also assumed that wear of bearings in technically dry friction conditions was dominated by wear of the bearing covers.

The volumetric wear was determined on the basis of diameters $D_{i j}$ measured using a micrometer in $J=5$ diametrical planes of the $i$-th bearing. As a reference, the diameter $D_{i 0}$ measured in the plane of division of the $i$-th bearing was taken as practically not worn.

The volumetric wear was determined from the formula (42):

$$
Z_{i} \approx B D_{i}\left(D_{i 0}-J^{-l} \sum_{j=1}^{j=s} D_{i j}\right)
$$

Knowing the volumetric wear $Z_{i}$ of the bearing cover, the diameter of the journal $D_{i}$, the reaction $R_{i}$ and the linear wear intensity $I_{h i}$ or wear indicator $K$ in 
the $i$-th bearing, it is possible to estimate the number of engine cycles $N$ from reaching the failure of the camshaft bearings.

The formula (43) [19] was used to estimate the number $N$ of engine cycles:

$$
\begin{aligned}
Z_{i} & =A_{c i} v_{z i} t=A_{c i} I_{h i} v_{\text {iave }} t=A_{c i} I_{h i} \pi D_{i} n_{\text {ave }} t= \\
& =A_{c i}\left[(\Delta h / s) p_{i}\right] \pi D_{i} n_{\text {ave }} t=A_{c i}(\Delta h / s)\left(R_{i} / A_{c i}\right) \pi D_{i} n_{\text {ave }} t= \\
& =K R_{i} \pi D_{i} n_{\text {ave }} t \\
\rightarrow & N=n_{\text {ave }} t=Z_{i} /(K R i \pi D i)
\end{aligned}
$$

where $v_{z i}=I_{h i} v_{\text {iave }}$ - linear wear speed, $v_{\text {iave }}=\pi D_{i} n_{\text {ave }}$ - average slip speed, $p_{i}=R_{i} / A_{c i}-$ average (contour) contact pressure, $A_{c i}$ - average (contour) contact surface, $R_{i}$ - reaction in the $i$-th bearing, $n_{\text {ave }}-$ average camshaft rotating speed.

The linear wear intensity $I_{h i}$ and the wear indicator $K$ in the $i$-th bearing can be determined from formula (44) [19]:

$$
I_{h i}=(\Delta h / s)=K p_{i}
$$

where: $\Delta \mathrm{h}$ - linear wear, $s$ - wear length.

The value of the linear wear intensity $I_{h}$ for camshaft bearings operating under mixed friction conditions was estimated as equal to $5.8 \cdot 10^{-8} \mathrm{~m} / \mathrm{m}$, which was close to the values obtained during the wear tests of the friction pair of the contact type: steel ring - AK9 alloy block lubricated with diesel oil with the addition of RME [16]. During the tests the force of $228 \mathrm{~N}$ loaded the block with diameter of 10 $\mathrm{mm}$. The determined value of the coefficient $K$ was $2 \cdot 10^{-14} 1 / \mathrm{Pa}$.

In turn, for the operation in technically dry friction conditions, the value of the $K$ coefficient was estimated to be close to the value obtained during the wear tests of the friction pair of contact type: steel disc - pin made of the AK12 aluminium alloy in the presence of air. The value of linear wear intensity was obtained from formula (45) and it was of $7.92 \cdot 10^{-8} \mathrm{~m} / \mathrm{m}$.

$$
I_{h}=\left(\Delta h_{p-d} / s_{p-d}\right)=\left[Z_{m p-d} /\left(\rho A_{p-d}\right)\right] / s_{p-d}
$$

where: $Z_{m p-d}=0.01 \mathrm{~g}$ - mass wear of pin, $\rho=2700$ $\mathrm{kg} / \mathrm{m}^{3}-$ density of AK12 alloy, $A_{p-d}=78.5 \mathrm{~mm}^{2}-$ disc-pin contact area, $s_{p-d}=250 \mathrm{~m}$ - wear length [2]. The force loading the pin with a diameter of $10 \mathrm{~mm}$ was $106 \mathrm{~N}$. The determined value of the coefficient $K$ was of $5.88 \cdot 10^{-14} 1 / \mathrm{Pa}$.

\section{Research Results and Discussion}

\subsection{Camshaft Bearings Lubrication System}

The obtained characteristics of the gear oil pump with internal toothing are shown in Fig. 8. In the range of considered engine speeds, its rise increases linearly both the pressure $p$ in the range of $70 \ldots 664$ $\mathrm{kPa}$, and the efficiency of the pump $Q_{r}$ in the range of $15.7 \ldots 149.2 \mathrm{~mm}^{3} / \mathrm{s}$.

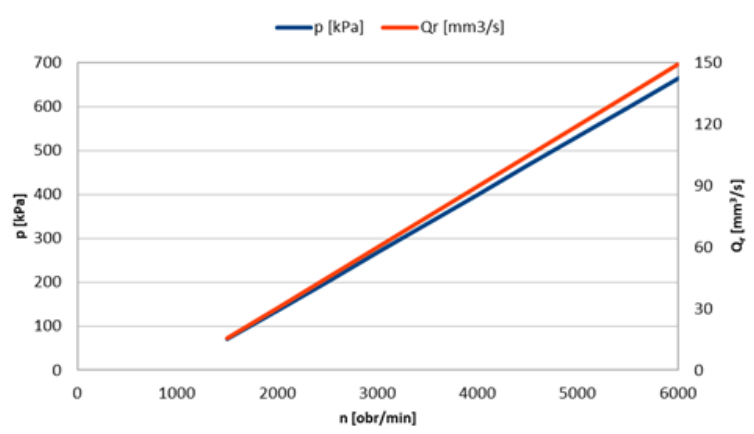

Fig. 8. Courses of pressure and efficiency of the gear oil pump with internal tooth as a function of engine speed

The obtained oil pressure distributions for the boundary condition at the inlet in the form of a mass flow of $0.00035 \mathrm{~kg} / \mathrm{s}$ are shown in Fig. 9.

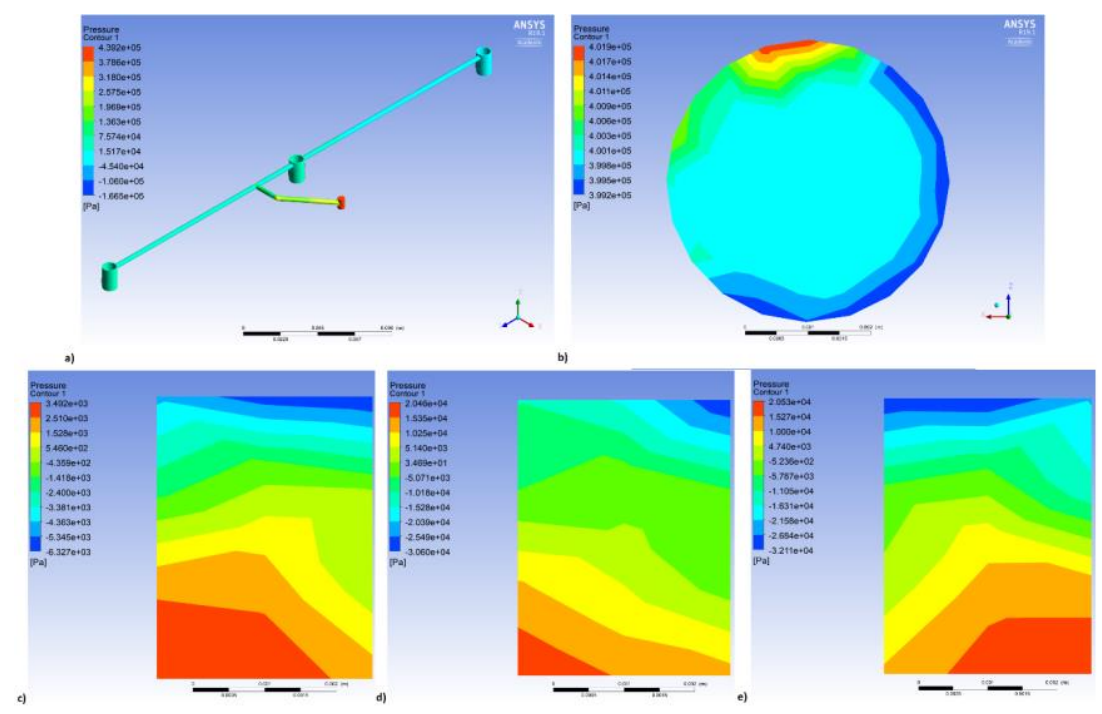

Fig. 9. Oil pressure distribution for the boundary condition on the inlet in the form of mass flow $0.00035 \mathrm{~kg} / \mathrm{s}$, a) for the oil main line, b) at the inlet, c) at the Outlet1, d) at the Outlet2, e) at the Outlet3 


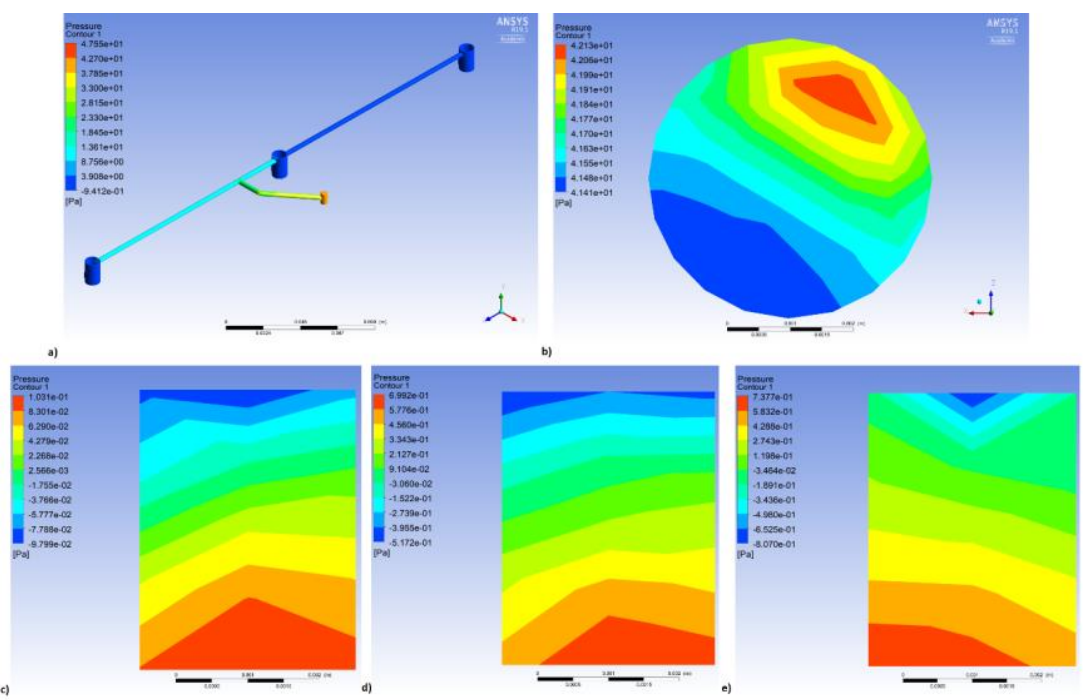

Fig. 10. Distribution of oil pressure for the boundary condition at the inflow in the form of a constant pressure of $400 \mathrm{kPa}$, a) for the oil main line, b) at the inlet, c) at the Outlet1, d) at the Outlet2, e) at the Outlet3

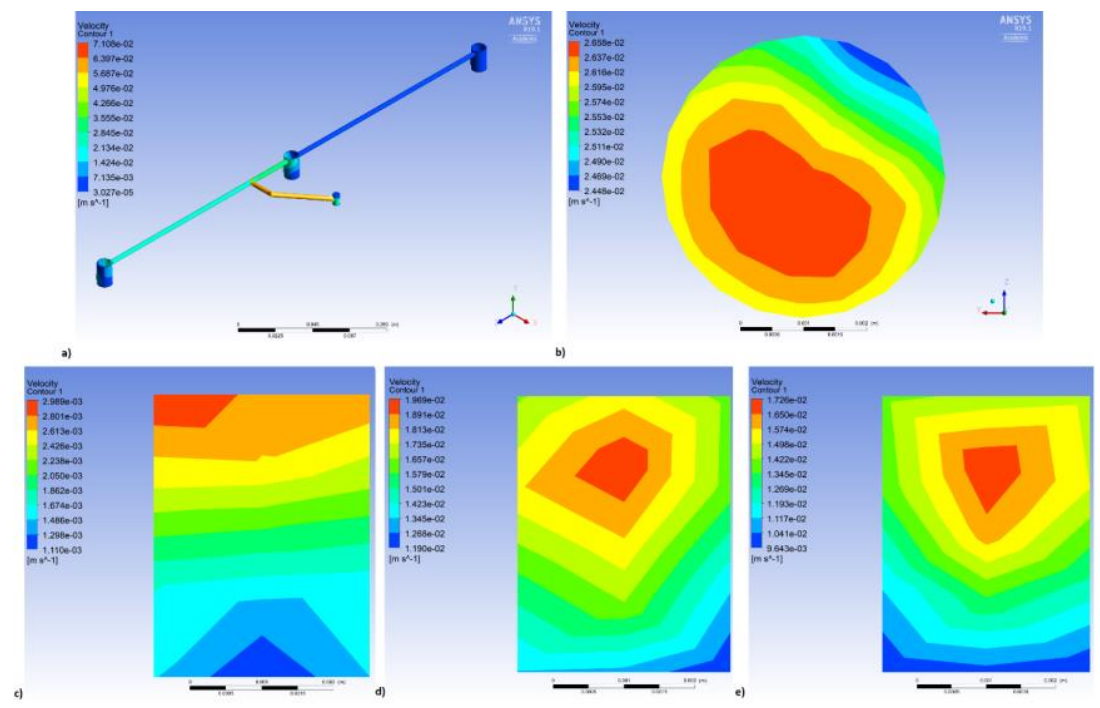

Fig. 11. Distributions of oil flow velocity for the boundary condition on the inflow in the form of a constant pressure of $400 \mathrm{kPa}$ a) for the oil main line, b) at the inlet, c) at the Outlet1, d) at the Outlet2, e) at the Outlet3.

a)

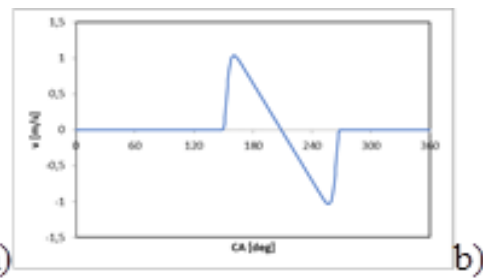

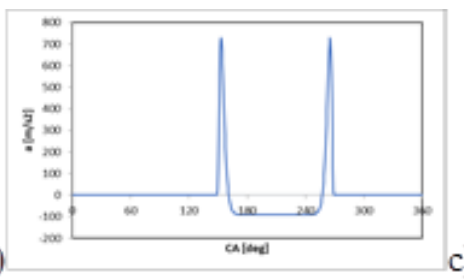

b)

c)

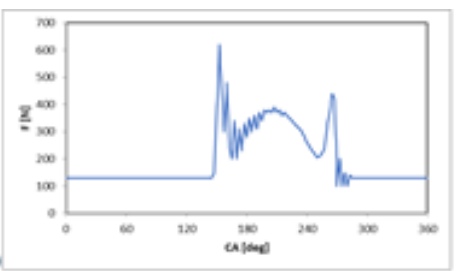

Fig. 12. Waveforms of a) speedy, b) acceleration of the tappet, c) force $F$ acting on the tappet as a function of the rotational angle of the camshaft

For the boundary condition at the inlet in the form of a constant pressure of $400 \mathrm{kPa}$ the pressure distributions are shown in Fig. 10 and the flow velocity distributions in Fig. 11.

Obtained negative pressure values may indicate the possibility of cavitation, but may also result from numerical causes. The figures show that the distributions at the oil outlets for camshaft bearings differ from each other in both speed and pressure. The most difficult conditions prevail in this respect at the outlet 1 .

\subsection{Loading of Camshaft Tappet}

Obtained graphs of speed, acceleration of tappet and the $F$ force acting on it are shown in Figures 12ac. Speeds reached the value of $1 \mathrm{~m} / \mathrm{s}$, and accelerations reached the value of $700 \mathrm{~m} / \mathrm{s}^{2}$. Figure $12 \mathrm{c}$ shows the vibrations caused by the action of valve springs in the model and cylinder pressure.

\subsection{Loading of Camshaft Bearings}

The obtained reaction values in camshaft bearings as a function of rotational angle for its average 
rotational speed of $750 \mathrm{rpm}$ and belt tension of $200 \mathrm{~N}$ are shown in Fig. 13, and for belt tension of $50 \mathrm{~N}$ in Fig. 14. Quadruple reduction of the toothed belt tension value may result in a reduction of bearing reactions up to $25 \%$. On the other hand, the graph obtained for the average rotational speed of the camshaft equal to $2000 \mathrm{rpm}$ and the belt tension of 200 $\mathrm{N}$ is shown in Fig. 15. Then the highest reaction values were obtained in the order of $1800 \mathrm{~N}$.

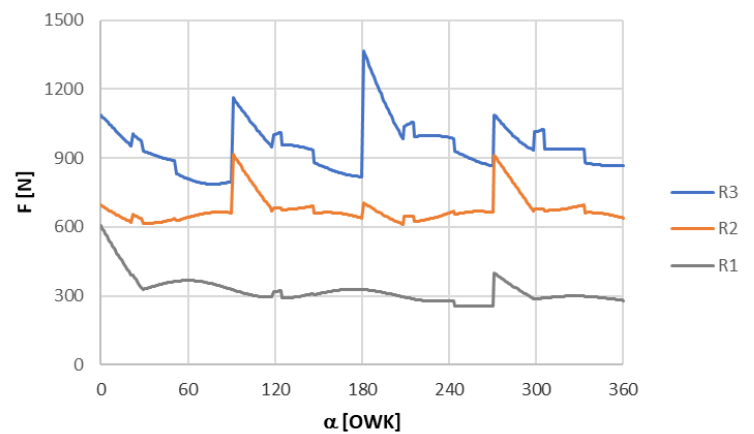

Fig. 13. Reaction values in camshaft bearings as a function of the rotational angle for its average rotational speed of $750 \mathrm{rpm}$ and belt tension of $200 \mathrm{~N}$

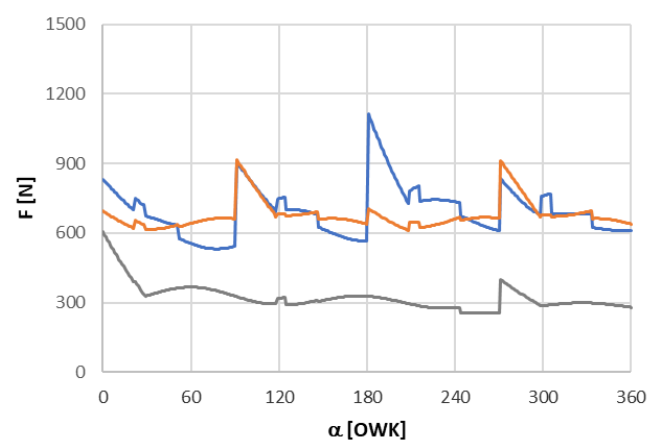

Fig. 14. Reaction values in camshaft bearings as a function of the rotational angle for its average rotational speed of $750 \mathrm{rpm}$ and belt tension of $50 \mathrm{~N}$

\subsection{Contact Pressure in Camshaft Bearings}

The distributions of contact pressure on the surfaces of the bearing covers for the selected fixed camshaft position and the rotational camshaft speed value of $750 \mathrm{rpm}$ are shown in Fig. 16, and for 2000 rpm in Fig. 17. The values of the average contact pressure do not exceed $5 \mathrm{MPa}$.

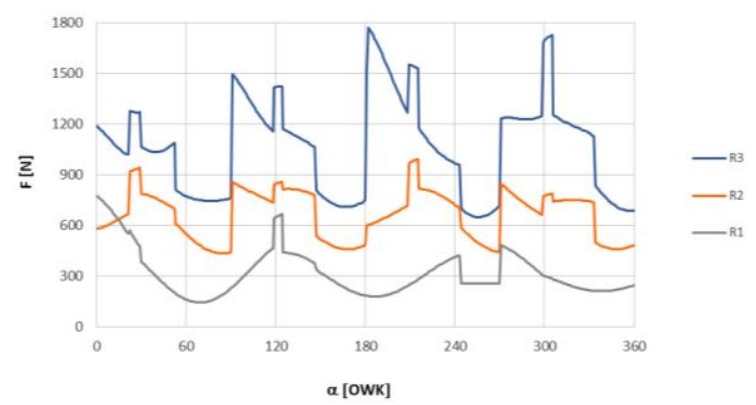

Fig. 15. Reaction values in camshaft bearings as a function of the rotational angle,

for its average rotational speed of $2000 \mathrm{rpm}$ and belt tension of $200 \mathrm{~N}$

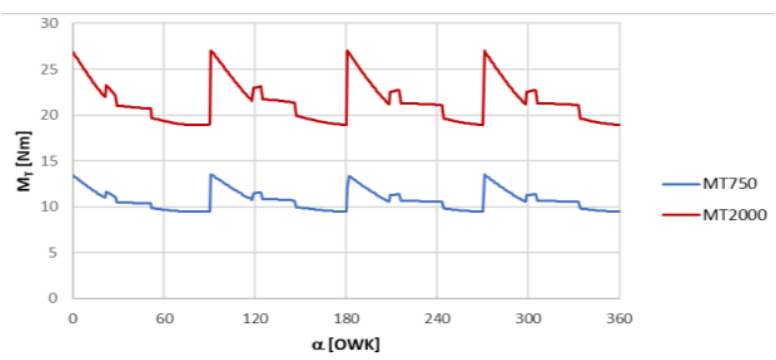

Fig. 18. The technically dry friction torque in camshaft bearings as a function of its rotational angle, for two values of camshaft rotational speed equal to $750 \mathrm{rpm}$ and $2000 \mathrm{rpm}$
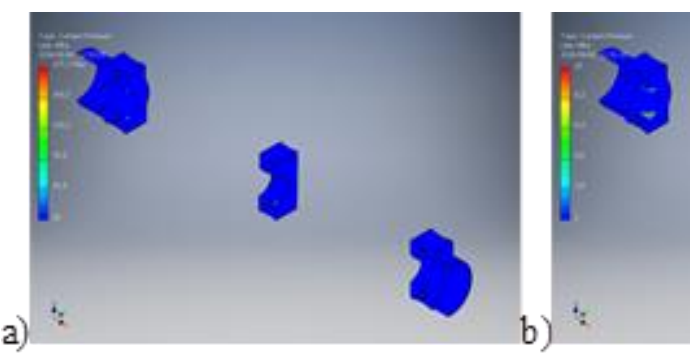
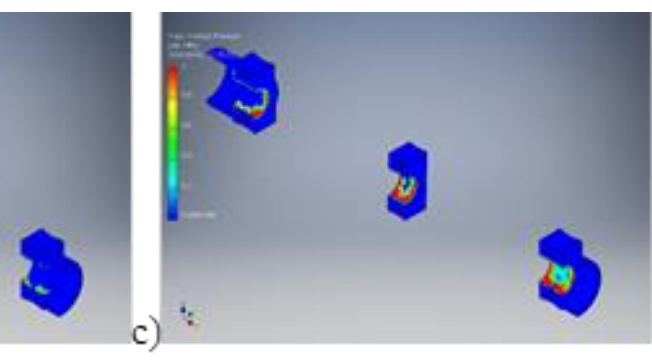

Fig. 16. Distribution of contact pressure on surfaces of the bearing covers for the rotational speed of the camshaft equal to $750 \mathrm{rpm}$
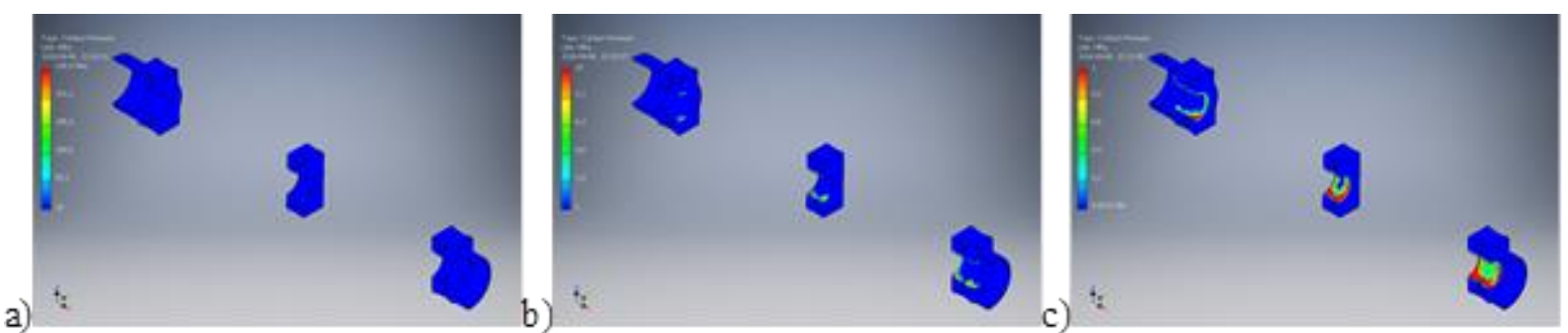

Fig. 17. Distribution of contact pressure on surfaces of the bearing covers for the rotational speed of the camshaft equal to $2000 \mathrm{rpm}$ 


\subsection{Friction Torque in Camshaft Bearings}

The course of the technically dry friction torque in the camshaft bearings as a function of the camshaft rotational angle, for two values of rotational speed equal to $750 \mathrm{rpm}$ and $2000 \mathrm{rpm}$ are shown in Fig. 18. The resistance for the latter is almost twice as high as for the first one.

To illustrate the effect of changing lubrication conditions, changes in the friction torque in the mostloaded bearing No. 3 for mixed friction and technically dry friction at the contact of the journal with the bearing cover were analyzed. Two cases of camshaft rotation speed of $750 \mathrm{rpm}$ and $2000 \mathrm{rpm}$ were considered.

For mixed friction conditions, for which the initial thickness of the oil film $h_{0}$ is $2 R a=1.6 \mu \mathrm{m}$, and the displacement resulting from the deformation of surface asperities is equal to $\Delta h=0.7 \mu \mathrm{m}$, the obtained value of the relative eccentricity was $\varepsilon=\left[C-\left(h_{0} / 2-\Delta h\right)\right] \cdot C$ ${ }^{1}=0.976$. The calculations were carried out, assuming the average value of the radius of surface asperities $\beta_{s}=0.014 \mathrm{~mm}$, the following parameters were determined: values of forces $R_{3}, R_{\text {con } 3}, F_{T R 3}, F_{T T 3}$ and $R_{H 3}$, average contact stress $p_{3}$, angle $\Phi_{3}$, resistance coefficient $f_{H 3}$, resistance moments $M_{T T 3}$ and $M_{T 3}$. The Table 1 shows the results of calculations.

The calculated values of average contact stresses $p_{3}$ in bearing 3 are similar to those determined in the FEM model, for both considered camshaft speeds, i.e. $750 \mathrm{rpm}$ and $2000 \mathrm{rpm}$.

In both analyzed cases of mixed and technically dry friction, it was noticed that the 2.7 fold increase in the cam roller rotation speed was accompanied by almost the same increases in the maximum bearing load and the maximum friction torque. The change of mixed friction to technically dry caused an almost 3.5fold increase in the resistance to motion for both considered rotational camshaft speeds.

\subsection{Wear of Camshaft Bearings}

The appearance of worn camshaft bearing shells from the head side is shown in Fig. 19. The appearance of worn bearing shells from the bearing cover side is shown in Fig. 20. The surfaces both on the side of the head and on the side of the bearing covers exhibit traces of rubbing through the camshaft journals. However, the degree of wear from the side of the bearing covers was much higher and the highest in the bearing 3 . The wear distribution in bearing 1 was the most uneven, which could result from the distribution of contact pressure and the load on only one side of the bearing. In bearings 2 and 3, the stress distributions were more evenly distributed and the load acted on both sides of the bearings.
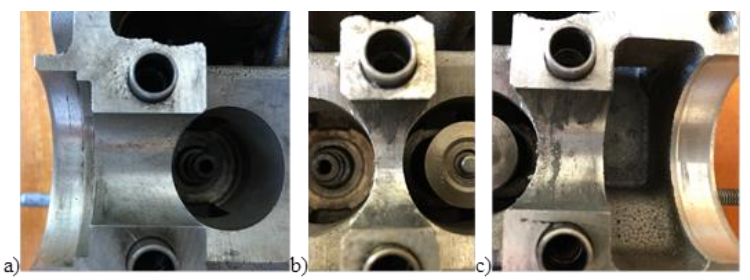

Fig. 19. Appearance of worn bearing bushings of camshaft slide bearings on the cylinder head side, a) bearing $3, \mathrm{~b}$ ) bearing 2 , c) bearing 1
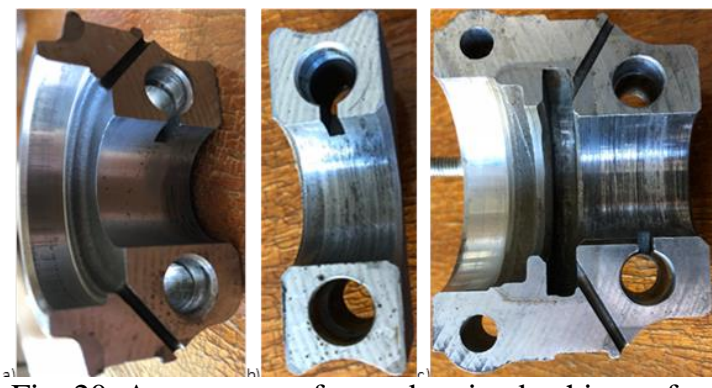

Fig. 20. Appearance of worn bearing bushings of cam roller bearings on the side of bearing covers, a) bearing $3, \mathrm{~b}$ ) bearing $2, \mathrm{c}$ ) bearing 1

The results of the volumetric wear measurements of bearings are given in Table 2 .

The volumetric wear $Z_{i}$ increased, although not directly proportional to the average load $R_{\text {iave }}$ of the bearings. The calculated number of $N_{1}, N_{2}$ and $N_{3}$ cycles of the engine operation until failure in the case of technically dry friction was almost three times lower than in the case of mixed friction.

\section{CONCLUSIONS}

1. Incorrect positioning of the gasket relative to the head can cause a 16-fold decrease in lubricating oil flow into the camshaft bearings.

Table 1. Calculated values of forces $R_{3}, R_{c o n 3}, F_{T R 3}, F_{T T 3}$ and $R_{H 3}$, average contact stress $p_{3}$, angle $\Phi_{3}$, resistance coefficient $f_{H 3}$, resistance moments $M_{T T 3}$ and $M_{T 3}$.

\begin{tabular}{|c|c|c|c|c|c|c|c|c|c|c|}
\hline$n$ & $R_{3}$ & $p_{3}$ & $R_{\text {con } 3}$ & $\Phi_{3}$ & $F_{T R 3}$ & $F_{T T 3}$ & $R_{H 3}$ & $f_{H 3}$ & $M_{T T 3}$ & $M_{T 3}$ \\
\hline$[\mathrm{rpm}]$ & {$[\mathrm{N}]$} & {$[\mathrm{MPa}]$} & {$[\mathrm{N}]$} & {$[\mathrm{rad}]$} & {$[\mathrm{N}]$} & {$[\mathrm{N}]$} & {$[\mathrm{N}]$} & {$[-]$} & {$[\mathrm{Nm}]$} & {$[\mathrm{Nm}]$} \\
\hline 750 & 1396 & 2.91 & 310 & 0.132 & 1384 & 184 & 1074 & 0.038 & 2.20 & 7.71 \\
\hline 2000 & 1768 & 3.67 & 310 & 0.132 & 1753 & 237 & 1458 & 0.063 & 2.81 & 9.76 \\
\hline
\end{tabular}

Table 2. Results of volumetric wear measurements of bearings

\begin{tabular}{|c|c|c|c|c|c|c|c|c|c|}
\hline$K$ & $Z_{1}$ & $R_{\text {lave }}$ & $Z_{2}$ & $R_{\text {2ave }}$ & $Z_{3}$ & $R_{\text {3ave }}$ & $N_{1}$ & $N_{2}$ & $N_{3}$ \\
\hline$[1 / \mathrm{Pa}]$ & {$\left[\mathrm{mm}^{3}\right]$} & {$[\mathrm{N}]$} & {$\left[\mathrm{mm}^{3}\right]$} & {$[\mathrm{N}]$} & {$\left[\mathrm{mm}^{3}\right]$} & {$[\mathrm{N}]$} & {$[-]$} & {$[-]$} & {$[-]$} \\
\hline $2 \cdot 10^{-14}$ & 16.21 & 300 & 31.56 & 700 & 44.32 & 1100 & 340765 & 298722 & 339155 \\
\cline { 1 - 6 } & & & & & & & 115872 & 101576 & 115325 \\
\hline $5.88 \cdot 10^{-14}$ & & & & & &
\end{tabular}


2. The model of the tappets-camshaft-bearings assembly developed using the Finite Element Method allows correct estimation of the average contact pressure values in the bearings.

3. The volumetric wear and resistance to motion in individual camshaft bearings increase with the load, the course of which for each bearing is different during the engine operation cycle.

4. An increase in rotational speed results in an increase in the total resistance to motion in the valvetrain and also an increase in the wear intensity of individual camshaft bearings.

5. In technically dry friction conditions occurring in camshaft bearings with wrong gasket position in relation to the head, the number of motor cycles to failure may be three times lower than in case of correct gasket positioning enabling mixed friction in these bearings.

\section{REFERENCES}

[1] Baldwin B.A. (1981) The Effect of Base Oil Viscosity on Simulated Valve Train, Wear, ASLE Transactions, 24(1), pp. 42-48.

[2] Dryzek E. (2008) Badania warstwy wierzchniej $\mathrm{w}$ aluminium i stopach aluminium za pomoca anihilacji pozytonów i metod komplementarnych/ Subsurface zone in aluminium and aluminium alloys studied by positron annihilation spectroscopy and other methods, rozprawa habilitacyjna, Kraków.

[3] Gangopadhyay A.K., Carter III R.O., Simko S., Gao H., Bjornen K.K, Black E.D. (2007) Valvetrain friction and wear performance with fresh and used low-phosphorous engine oils, Tribology Transactions, 50(3), pp. 350-360.

[4] Gangopadhyay A., Soltis E., Johnson M.D. (2004) Valvetrain friction and wear: Influence of surface engineering and lubricants, Proceedings of the Institution of Mechanical Engineers, Part J: Journal of Engineering Tribology, 218(3), pp. 147156.

[5] http://www.sebros.eu/aluminium/wlasciwoscialuminium-i-stopow-aluminium/ Available at: 2018.09.15.

[6] Kopeliovich D., Camshaft Bearings, http://www.substech.com/dokuwiki/doku.php?id=ca mshaft_bearings, Available at: 2018.09.15.

[7] Niezgodziński M.E., Niezgodziński T., Wzory (1974) Wykresy i Tablice Wytrzymałościowe, Warszawa, PWN.
[8] Nowicki B. (1991) Chropowatość i falistość powierzchni, Warszawa, WNT.

[9] Patir N, Cheng H.S. (1979) Application of average flow model to lubrication between rough sliding surfaces. Journal of Lubrication Technology, 101(2), pp. 220-229.

[10] Profito F.J. (2015) On the development of advanced techniques for mixed-elastohydrodynamic lubrication modelling of journal and sliding bearing systems, doctoral thesis, University of São Paulo, São Paulo, doi: 10.13140/RG.2.1.2383.6249.

[11] Roylance B.J., Bovington C.H., Wang G., Hubbard A., (1991) Paper VI (iii) Running-in wear behaviour of valve-train systems, Tribology Series, 18, pp. 143-147.

[12] Shirahama S., Hirata M. (1989) The effects of engine oil additives on valve train wear, Lubrication Science, 1(4), pp. 365-384.

[13] Stryczek J. (2007) Koła zębate maszyn hydraulicznych, Wrocław, Oficyna Wydawnicza Politechniki Wrocławskiej.

[14] Szeri A.Z. (2000) Hydrodynamic and Elastohydro-dynamic Lubrication, in Bhushan B., Modern Tribology Handbook, Two Volume Set, 1st Edition, CRC Press.

[15] Teodorescu M., Balakrishman S., Rahnejat H. (2004) Integrated tribological analysis within a multiphysics approach to system dynamics, 31st LeedsLyon Symposium. Life Cycle Tribological Analysis, Leeds, UK.

[16] Wanke P., Batko B. (2008) Analiza zużycia skojarzeń ślizgowych typu stal - aluminium smarowanych olejem napędowym $\mathrm{z}$ dodatkiem RME, Inżynieria Rolnicza 1(99), pp. 383-388.

[17] Wu C., Zheng L. (1989) An average Reynolds equation for partial film lubrication with a contact factor, ASME Journal of Tribology, 111(1), pp. 188191.

[18] Zwierzchowski M. (2005) Procesy zużywania elementów układu rozrządu silników ZS/ Wears process of diesel engines timing gear systems, Eksploatacja i Niezawodność, 2, pp. 57-60.

[19] Zwierzycki W. (ed) (1990) Wybrane zagadnienia zużywania się materiałów w ślizgowych węzłach maszyn, PWN, Warszawa-Poznań, 